\title{
From the Editor
}

\author{
NIH Austerity? \\ Nathan S. Blow, PhD. \\ Editor-in-Chief, BioTechniques
}

W ith all the talk surrounding the importance of funding science, it's always surprising to see the turmoil when it comes to deciding on the budgets of major research funders every year. And 2013 will prove to be no different.

In fact, the coming year might turn out to be one of the most anxiety-inducing thus far for the scientific research community. The reason for this enhanced concern is the possibility that a series of pre-programmed budget cuts (caused by sequestration) will happen if Congress cannot come to a resolution on how best to deal with the growing budget deficit.

These cuts are not only a direct result of the desire to reduce our national debt, but also the inability of congressional committees to arrive at a consensus on how spending cuts should be implemented. This failure has triggered the possibility of a $7.8 \%$ cut in funding to all non-military governmental agencies - that would include major funders of scientific research such as the National Institutes of Health (NIH) and the National Science Foundation (NSF). Even without cuts, NIH is still facing $0 \%$ growth in federal funding for 2013 (or negative growth when inflation is factored in) based on the current proposed budget. A 7.8\% cut, however, would mean an immediate reduction in the number of external grants awarded and the possible closure of other projects and initiatives (by one account, the result would be 2300 fewer new and competing grants in 2013).

Many predict that Congress will come to a resolution prior to the deadline and avoid such automatic across-the-board cuts. However, will this possibility be enough to calm the scientific community when it comes to the future of government-sponsored research funding? And more importantly, should it?

The coming months will clearly prove challenging for the leadership of agencies such as NSF and NIH. How would NIH deal with the loss of nearly $\$ 3$ billion from their budget (if a $7.8 \%$ cut is enacted)? Is the NIH already overextended? Obviously, it is important to advocate for more funding of science research, and clearly spell out to members of Congress and the general public the importance of basic research, but similar to many companies in this economically difficult time, it is also important to clearly understand fiscal limitations and make proper plans. The unprecedented growth of the NIH budget for many years resulted in incredible funding opportunities. But now, with the strong possibility of scaling back on the horizon, $\mathrm{NIH}$ will need to clearly prioritize funding opportunities and assess how funds are allocated if the agency is going to maintain a broad scientific mandate-not a simple task by any means.

Much to their credit, leaders at NIH have already made strong steps in this direction. Earlier this year, the institute examined a plan to limit awardees to $\$ 1.5$ million in federal grants in an effort to fund more applications. Such measures are becoming a necessity as the institute struggles to find the best mechanism to fund a growing number of research projects with less money.

Basic research remains critical to advancing health and disease treatment in the US and throughout the rest of the world. With pharmaceutical companies and biotechnology firms reducing the size of their research and development efforts, the strain to support basic discovery efforts will inevitably fall back on government funding. In the end, whether or not NIH faces greater cuts at the start of 2013 remains to be determined by Congress, but what is needed now is seeing this as a moment in time for reflection and discussion on the future of science funding.

As always, please share your thoughts with us by posting at our Molecular Biology Forums under "To the Editor" (http://molecularbiology. forums.biotechniques.com) or sending an email directly to the editors (bioeditor@biotechniques.com).

BioTechniques 53:67 (August 2012) doi 10.2144/000113895

To purchase reprints of this article, contact:

biotechniques@fosterprinting.com

\author{
It is important to \\ advocate for funding \\ of science research, and \\ spell out to members of \\ Congress the importance \\ of basic research
}

